\title{
TERCEIRIZAÇÃO DE SERVIÇOS: A MODERNA ESTRATÉGIA EMPRESARIAL NA GESTÃO ORGANIZACIONAL
}

Aline Aparecida de Oliveira, Ana Carolina da Silva, Christian Roberto de Godoy, Natália Sayuri Suzuki, Thais Rubia Ferreira Lepre

Universidade do Oeste Paulista, Curso de Administração, Presidente Prudente, SP. E-mail: thaisrubia@unoeste.br

\section{RESUMO}

Com a globalização e consequente aumento da competitividade, as organizações vem buscando soluções rápidas na gestão de seus negócios. Neste contexto, a terceirização surge como uma possível solução, considerando que possibilita que as empresas centrem-se na atividade fim e transfiram a responsabilidade das atividades de apoio a organizações qualificadas e especializadas. Porém, por se tratar de um assunto relativamente recente entre os gestores, é importante identificar as vantagens e desvantagens de se terceirizar os serviços de apoio dentro das empresas, e este é o objetivo deste artigo, que tem abordagem qualitativa e pesquisa bibliográfica como método de investigação. Os resultados mostram a redução dos custos, a agilização dos processos e a inovação entre as vantagens, enquanto a falta de critério na escolha do prestador e o choque cultural entre as desvantagens. Conclui-se que a terceirização é uma importante ferramenta para as organizações, desde que todos os aspectos sejam observados.

Palavras-chave: Terceirização. Vantagens. Desvantagens. Competitividade. Empresas.

\section{SERVICES OUTSOURCING: A MODERN BUSINESS STRATEGY IN ORGANIZATIONAL MANAGEMENT}

\begin{abstract}
Com a globalização e consequente aumento da competitividade, as organizações vem buscando soluções rápidas na gestão de seus negócios. Neste contexto, a terceirização surge como uma possível solução, considerando que possibilita que as empresas centrem-se na atividade fim e transfiram a responsabilidade das atividades de apoio a organizações qualificadas e especializadas. Porém, por se tratar de um assunto relativamente recente entre os gestores, é importante identificar as vantagens e desvantagens de se terceirizar os serviços de apoio dentro das empresas, e este é o objetivo deste artigo, que tem abordagem qualitativa e pesquisa bibliográfica como método de investigação. Os resultados mostram a redução dos custos, a agilização dos processos e a inovação entre as vantagens, enquanto a falta de critério na escolha do prestador e o choque cultural entre as desvantagens. Conclui-se que a terceirização é uma importante ferramenta para as organizações, desde que todos os aspectos sejam observados.
\end{abstract}

Keywords: Outsourcing. Advantages. Disadvantages. Competitiveness. Companies. 


\section{INTRODUÇÃO}

A constante busca das organizações em se adaptar as mudanças e estar sempre à procura de métodos para se fortalecer no mercado, a terceirização tem sido bastante estudada por se tratar de uma opção administrativa para a gestão das organizações.

Seu surgimento ocorreu nos Estados Unidos, por volta de 1940 impulsionada pela fabricação do armamento do próprio país e de seus aliados na $2^{\text {a }}$ guerra mundial.

Segundo Queiroz (1992, p.34):

A terceirização foi muito aplicada ao longo da guerra, pois as indústrias da época precisavam concentrar-se na produção, cada vez melhor, das armas necessárias para a manutenção da superioridade aliada, e então descobriram que algumas atividades de suporte à produção de armamentos poderiam ser passadas a outros empresários prestadores de serviços, mediante a contratação desses.

Nota-se que a terceirização surgiu da necessidade das indústrias de armamentos focarem na qualidade e produção de sua atividade-fim transferindo a terceiros as atividades de suporte.

$\mathrm{O}$ ato de terceirizar significa transferir um processo interno para um terceiro realizá-lo, esse processo pode ser a produção de bens e serviços como também serviços acessórios, ou seja, as chamadas atividades "meio".

Consiste a terceirização na possibilidade de contratar terceiro para a realização de atividades que não constituem o objetivo principal da empresa. Essa contratação pode envolver tanto a produção de bens e serviços, como ocorre na necessidade de contratação de serviços de limpeza, de vigilância ou até serviços temporários. (MARTINS, 2002, p. 170).

Pode-se dizer que existem dois tipos de terceirização: a terceirização das atividades descritas como "meio" que consistem nos serviços de apoio de uma empresa, ou seja, utilizadas como suporte à manutenção da mesma e também as atividades denominadas "fim" que são aquelas primordiais no processo produtivo.

Então fica claro que a diferença está na finalidade da atividade exercida, como explica Queiroz (1992), as atividades meio são ações administrativas, ou intermediárias no processo produtivo, são aquelas que apoiam ou suportam a produção sem interferir diretamente na qualidade ou no produto em si. Já as atividades fim fazem parte essencialmente do processo produtivo, estão diretamente ligados à qualidade e fabricação do produto.

Sendo assim, o foco desta pesquisa será levantar as vantagens de desvantagens de se terceirizar serviços de apoio dentro das empresas, ou seja, serão estudadas as atividades meio. 
No atual cenário competitivo das empresas há uma busca incessante por formas de se obter vantagens competitivas, qualidade e redução de custos e a terceirização foi uma das formas de gestão que as empresas decidem adotar, sendo assim existem inúmeras vantagens e desvantagens que devem ser analisadas antes de sua implantação.

Foram identificadasas vantagens de se terceirizar as atividades meio, que de acordo com Pagnoncelli (1993) destacam-se: a melhoria da qualidade e da supervisão de serviços, redução de custos, foco no objetivo principal da empresa, agilização (desburocratização), criação de ambiente propício ao surgimento de inovações.

Em relação a melhoria de qualidade e supervisão de serviço, quando delegado a terceiros, deve-se levar em conta que devido a quantidade de serviços prestados há a especialidade e a experiência na prestação, tornando-se mais ampla, pois a terceirizada tem foco específico em determinada área.

Para Martins (2001, p. 42):

A principal vantagem, sob o aspecto administrativo, seria a de se ter a alternativa para melhorar a qualidade do produto ou serviço vendido e, também, a produtividade. Seria uma forma também de se obter um controle de qualidade total dentro da empresa [...]

A qualidade sem dúvida é o ponto essencial quando uma empresa resolve terceirizar seus serviços, pois não faria sentido a contratação de serviços terceirizados se não houvesse possibilidade de melhoria na qualidade ou pelos menos que se mantenha a mesma.

A segunda vantagem que a empresa obtém ao contratar o serviço de um terceirizado é a redução de custos, considerada uma das principais vantagens em se terceirizar, pois, com isso ela pode reduzir maquinários, espaço físico e gasto com capacitação de funcionários além de encargos trabalhistas.

Com base na redução de custos com a terceirização, Queiroz (1992, p.128-129) menciona os seguintes itens a serem considerados: 
Tabela 1. Custos considerados na terceirização

\begin{tabular}{|l|l|}
\hline Acidentes no trabalho & Supervisão \\
\hline Remuneração dos 15 dias iniciais de afastamento & Segurança no trabalho - EPI e EPC \\
\hline Estabilidade da Lei 8.213/91 - Art. 118 & Uniformização \\
\hline Socorro médico emergencial & Controle administrativo de pessoal \\
\hline Recrutamento, Seleção e Treinamento & Ociosidade da mão-de-obra \\
\hline Admissão e Demissão & Acréscimo de mão-de-obra - substituições \\
\hline Mão-de-obra para picos de trabalho & Absenteísmo \\
\hline $\begin{array}{l}\text { Ferramentas, Instrumentos, Equipamentos e e } \\
\text { Materiais }\end{array}$ & Custos invisíveis \\
\hline
\end{tabular}

Fonte: Adaptado de Queiroz (1992, p.128-129)

A vantagem que mais desperta o interesse dos gestores que decidem terceirizar seus serviços é a redução de custos, porém muitos autores advertem para o risco de deixar que apenas essa vantagem seja considerada na decisão de se terceirizar, pois existem outros fatores que são tão importantes quanto a simples redução dos custos.

Também é considerada uma vantagem de se terceirizar, o fato de que quando a empresa passa à responsabilidade do serviço a terceiro, ela pode focar no objetivo principal, ou seja, em suas atividades fim.

De acordo com Barros (2002, p. 626):

[...] mantêm a empresa contratante com foco no próprio negócio - passando as atividades auxiliares a fornecedores, que, exatamente por ter essa atividade como foco principal e razão de existência de suas empresas, podem oferecer alto grau de especialização e investir no desenvolvimento das pessoas e de tecnologia.

Com a competitividade do mercado atual as empresas precisam focar em qualidade, melhores preços, conquista de clientes e a fidelização dos mesmos, sendo assim a terceirização de serviços de apoio da empresa tem sido uma das saídas mais vantajosas para os empresários que transferem a execução de atividades meio a terceiros tendo assim mais tempo para focarem no objetivo principal da empresa.

Outra vantagem da terceirização seria a agilização (desburocratização), que visa uma maior rapidez nos processos operacionais, diminuindo o tempo gasto com treinamento e capacitação de funcionários para exercer determinada função.

Para Giosa (1995, p. 18) "sem preocupar-se operacionalmente com as ditas atividades secundárias, as empresas terão mais competividade e agilidade na consecução de suas operações e mais rapidez na tomada de decisão em razão dos novos objetivos." 
Em um mundo onde as empresas buscam a todo instante se tornarem mais competitivas e mais lucrativas, a agilidade é fundamental e a terceirização de serviços traz para as empresas tomadoras uma maior rapidez nos processos operacionais.

Por fim, a inovação traz como ponto positivo o fato do terceiro estar sempre se modernizando conforme vão surgindo tecnologias mais atuais, pois por ser o foco principal da empresa, o terceirizado tem como obrigação ter um serviço de maior qualidade.Para Barros (2002, p. 630) "a principal expectativa para empresa ao contratar os serviços de um fornecedor especializado é conseguir inovação e melhoria de processos e redução de custos."Por ser uma empresa especializada naquele determinado serviço, a terceirizada normalmente tende a estar buscando novas formas de melhor atender seus clientes, se modernizando, inovando.

Já com relação as desvantagens, Queiroz (1993) aborda as seguintes: falta de critério adequado na escolha do prestador de serviço, problemas com a especialização necessária do terceirizado, choque cultural entre o tomador e o prestador de serviços.

Um grande problema enfrentado pelas empresas que decidem terceirizar seus serviços é a falta de critério adequado na escolha do prestador, o que acaba trazendo aborrecimentos para a empresa tomadora, além da falta de comprometimento e de qualificação do prestador de serviço contratado.

Para Martins (2001, p. 46), "um dos principais riscos da terceirização é contratar empresas inadequadas para realizar os serviços, sem competência e idoneidade financeira".A empresa tomadora precisa estabelecer critérios no momento da escolha do prestador de serviços, verificando a competência, a idoneidade, a qualidade do serviço e principalmente o comprometimento da empresa para que após feita a contratação não haja surpresas desagradáveis.

Entre as desvantagens, pode-se dizer que quando uma empresa resolve terceirizar seus serviços ela necessita ter muita cautela nesse processo, pois em sua grande maioria irá ocorrer um choque cultural entre as culturas da empresa tomadora e da empresa prestadora de serviços.

Segundo Giosa (1997, p. 12) “cada empresa à luz da sua cultura e filosofia de ação deverá repercutir internamente os graus de dificuldade e de facilitação para chegar a um equilíbrio decisório, sempre com a visão estratégica, para a implementação da terceirização."Cada empresa possui sua própria cultura interna sendo assim deve-se ter cautela quando uma atividade passar a ser executada por terceiros, pois os funcionários da empresa terceirizada também possuem uma cultura própria podendo ocasionar um choque entre a cultura da sua empresa com a da empresa tomadora sendo necessária uma adequação entre essas culturas. 
Pode-se dizer que um dos problemas que ocorre na terceirização seja a falta de especialização necessária do terceirizado escolhido na execução de determinadas atividades a que foram contratados.

Segundo Diniz (1996, p. 204)

consiste na existência de um terceiro especialista, chamado de fornecedor ou prestador de serviços, que com competência, habilidade e qualidade técnica, presta serviços especializados ou produz bens, em parceria, para a empresa contratante, chamada tomadora ou cliente.

A falta de especialização necessária do prestador é um grande problema da terceirização, pois muitas vezes é decorrente da falta de capacitação do funcionário ou mesmo do interesse da terceirizada em investir em treinamentos adequados, o que pode trazer conseqüências desagradáveis para a empresa tomadora.

Uma desvantagem que também deve ser considerada são os problemas decorrentes da sua implantação, pois como visto acima a falta de critério na escolha do prestador pode trazer problemas futuros, porém mesmo que haja todo um cuidado nesta escolha, podem ocorrer problemas não previstos, mas que podem trazer prejuízos.

Para as empresas, o maior problema da terceirização se dá no processo de implantação. No caso da contratada não cumprir seus compromissos, a contratante terá que supri-los. Se a contratada também não for capaz de realizar as atividades a quais se propôs, e se estas forem importantes para a manutenção do negócio (como os serviços de higiene e informática, por exemplo) a contratada terá que "tampar o buraco" o mais urgentemente possível, o que gerará gastos adicionais. (ASSIS, 2010).

Caso a empresa terceirizada por algum motivo venha a não conseguir cumprir com as atividades a que foi contratada, infelizmente a empresa tomadora terá que providenciar que o serviço seja executado, pois mesmo que haja um contrato previamente estabelecido e que o não cumprimento tenha conseqüências para a prestadora, algumas atividades são importantes para a manutenção da empresa tomadora, sendo necessário que sejam feitos levando muitas das vezes a custos adicionais.

Diante deste contexto, o objetivo deste artigo é identificar as vantagens e as desvantagens de terceirizar serviços de apoio dentro das organizações.

\section{METODOLOGIA}

No artigo em questão foi utilizada a abordagem qualitativa, que segundo Gibbs (2009, p. 09) “[...] parte da idéia de que os métodos e a teoria devem ser adequados àquilo que se estuda”. 
E como o objeto de estudo deste artigo são as vantagens e desvantagens da terceirização, esta abordagem subjetiva é a que mais se adéqua.

Como instrumento de coleta de informações, foi utilizada a pesquisa bibliográfica que de acordo com Marconi e Lakatos (2010, p. 142) "[...] é um apanhado geral sobre os principais trabalhos já realizados, revestidos de importância, por serem capazes de fornecer dados atuais e relevantes relacionados com o tema." Ou seja, este tipo de pesquisa é viabilizado através de materiais já publicados, assim, este estudo foi realizado por meio de livros, revistas e artigos.

\section{RESULTADOS E DISCUSSÃO}

Com base nos dados apresentados nesta pesquisa, foi possível elencar diversas vantagens, bem como desvantagens da terceirização dos serviços de apoio dentro das organizações.

Entre as vantagens encontradas estão: a melhoria da qualidade e supervisão de serviço, a redução dos custos, a possibilidade da empresa poder focar mais no objetivo principal da empresa, a agilização dos processos e a inovação. Entre as desvantagens levantadas tem-se: como a falta de critério na escolha do prestador bem como os problemas com a especialização do mesmo, e o choque cultural entre a cultura do prestador e da tomadora e os problemas decorrentes da implantação da terceirização dentro da empresa.

\section{CONCLUSÃO}

Terceirizar serviços de apoio vem se tornando uma importante alternativa para gestores dos mais diversos tipos de organização. A possibilidade de centrar na atividade fim e transferir a responsabilidade de execução das atividades de apoio para empresas especializadas é vista como forma de melhorar a competitividade.

Neste sentido, este estudo buscou identificar as vantagens e as desvantagens de terceirizar serviços de apoio dentro das organizações. E diante dos resultados encontrados, conclui-se que em meio as diversas vantagens e desvantagens, cabe a cada gestão analisar cuidadosamente os prós e os contras desta estratégia a fim de que ele seja uma aliada na busca pelo sucesso organizacional.

\section{REFERÊNCIAS}

ASSIS, Maria OLívia Elias Gomes de. As várias faces da terceirização de serviços. (Em: $<$ http://www.administradores.com.br/artigos/marketing/as-varias-faces-da-terceirizacao-deservicos/46348/>. Acesso em: 17 mai. 2015. 
BARROS, Laurade. Gerenciamento do Trabalho Terceirizado. In: BOOG, Magdalena (Coord): Manual de Gestão de Pessoas e Equipes: Estratégias e Tendências. São Paulo: Gente, 2002.

DINIZ, José Janguiê Bezerra. "O Fenômeno da Terceirização". Revista LTr, LTr Editora Ltda., São Paulo - (SP), Vol. 60, no 02: 204-209, fevereiro de 1996.

GIBBS, Graham. Analise de dados qualitativos. Porto Alegre: Artmed, 2009.

GIOSA, Lívio Antônio. Terceirização: uma abordagem estratégica. 5.ed São Paulo: Pioneira, 1997.

GIOSA, Lívio Antônio. Terceirização: uma abordagem estratégica. 4.ed São Paulo: Pioneira, 1995.

MARCONI, Marina de Andrade; LAKATOS, Eva Maria. Fundamentos de metodologia científica. 7. ed. São Paulo: Atlas, 2010.

MARTINS, Sérgio Pinto. A Terceirização e o direito do trabalho.São Paulo: Atlas, 2001.

MARTINS, Sérgio Pinto. Direito do trabalho. 15. ed. São Paulo: Atlas, 2002.

PAGNONCELLI, Dernizo.Terceirização e Parceirização: estratégias para sucesso empresarial.Rio de Janeiro: D. Pagnoncelli, 1993.

QUEIROZ, Carlos Alberto Ramos de.Manual de Terceirização. 7. ed. São Paulo: Sts, 1992.

SILVA, Ciro Pereira. A Terceirização Responsável: modernidade e modismo.São Paulo. LTr, 1997 